\title{
Novas exigências de formação
}

Antonio Fausto Neto

\section{Resumo}

Examina-se fatores que impõem novas exigências de processos formativos do jornalista, a partir do cenário da "sociedade midiatizada", cujas dinâmicas e processos causam alterações na cultura e rotinas jornalísticas, na própria atividade "protagonica" dos seus atores e, respectivamente em características identitárias da profissão. Sublinha-se que decisão jurídica em considerar desnecessário o diploma universitário, para o exercício da profissão, é apenas um dos elementos deste processo, que faz emergir interrogações, mas também desenha debates acerca de outros formativos curriculares que reforçam a exigência de diplomas e certificação universitários.

Palauras-chave:

Jornalismo, Midiatização, Reconhecimento

\section{Sobre o autor}

Graduado em Jornalismo pela Universidade Federal de Juiz de Fora (1972), mestre em Comunicação pela Universidade de Brasília (1977), doutor em Sciences de La Comunication Et de L'information - Ecole des Hautes Etudes en Sciences Sociales França (1982) e estudos de pós-doutorado na UFRJ - RJ (1990).

Professor titular da Universidade do Vale do Rio dos Sinos (UNISINOS) fausto@unisinos.br

\section{New demands on journalism education}

\section{Abstract}

The study examines factors that impose new demands of formative processes for journalists, through the "mediatic society" panorama, whose dynamics and processes cause alterations in jurnalistic culture and routines, in the "protagonist" activity of its actors and also in identifying features of the profession. It emphasizes that the juridical decision that considers the degree for the exercise of the profession unnecessary is only one of the elements of this process, which brings out questions, but also draws debates on other curricular formative processes that accentuate the requirement of university degrees and certification.

\section{Key words:}

Journalism, Mediatization, Recognition 
A recente decisão do STF, considerando desnecessária a exigência do diploma universitário em jornalismo, para o exercício desta profissão, suscitou desconfortos e desolações no âmbito daqueles setores que viam neste certificado um símbolo de reconhecimento de qualidade, enquanto exigência para o trabalho jornalístico. Noutros, visível satisfação, ao comungar com a idéia daquele elevado Fórum para quem fazer jornalismo - a exemplo, possivelmente de outras profissões - exigia apenas "sensibilidade e boa redação"... Reações polares em meio à ausência de reflexões - a exceção de uma ou outra reação. Lamenta-se a inexistência quase que generalizada, de manifestações da universidade, de quem se esperava a defesa, de caráter teórico-epistemológicopedagógico, sobre a obrigatoriedade do diploma. Também, das sociedades científicas de natureza comunicacional-jornalística, em cujos âmbitos são abrigados grupos de estudos e nos quais se reflete sobre questões que envolvem esta prática sócio-simbólica, a partir da produção intelectual e acadêmica que se faz no país.

A presente reflexão não se fixará sobre as indignações e sentimentos desolados, preferindo avançar novas hipóteses sobre a exigência do diploma, fazendo um outro caminho. Ou seja, mostrar que a transformação da "sociedade dos meios" para a "sociedade midiatizada" impõe profundas mutações no campo jornalístico, especialmente nos processos de noticiabilidade, redimensionado as características do trabalho e a formação dos seus atores - os jornalistas. Procuraremos indicar que, a despeito do "episódio do STF", o trabalho jornalístico requer novos processos formativos considerando a complexidade e a repercussão das transformações tecno-discursivas da midiatização sobre o campo e prática jornalística. E, finalmente, que tais processos envolvem um aspecto fundamental: a importância da certificação universitária, mas segundo novos desenhos e concepções curriculares que não reforcem tendências autorreferentes, como a idéia de um "currículo autônomo" dissociado desta nova ambiência comunicacional. Assim, pretende-se desenvolver nas linhas que seguem, a hipótese segundo a qual a midiatização impõe mutações no trabalho jornalístico e no reconhecimento de seus atores, colocando novas exigências de processos formativos segundo grades curriculares que abriguem referências (disciplinas e matérias) que reflitam as complexidades que envolvem a relação do jornalismo com a sociedade midiatizada contemporânea.

\section{Impactos da midiatização sobre o jornalismo}

Elaborando o conceito de acontecimento, Alsina destaca o status da "sociedade midiática" como aquela que "fazia acontecer" (2009:126). Enfatiza, certamente o papel dos meios de comunicação e sua centralidade neste processo, algo talvez que fosse mais
Midiatização impõe mutações

no trabalho jornalístico e no reconhecimento de seus atores, colocando novas exigências de processos formativos 
típico da "sociedade dos meios". Ou seja, aquela que se caracterizava pela existência dos meios e o papel do seu campo, de seus atores e processos - especialmente o dos jornalistas - na tarefa de tematização e publicização de questões referentes aos demais campos sociais. Nesta sociedade, o jornalismo desempenhava um tipo de mediação específica, destacando-se por seu trabalho de "porta de acesso" da sociedade aos "sistemas abstratos" (Giddens, 1992), tarefa que estava confiada aos seus peritos, no caso os jornalistas. Nela, a prática jornalística caracterizava-se por sua tarefa representacional, consistindo na revelação de valores e de questões que eram tecidas nas fronteiras dos demais campos sociais. Esta atividade estava referida em princípios que davam sustentação ao fazer jornalístico, como um ato central. Tal ato de articular o contato entre instituições e a sociedade gerou, ao longo dos anos, reflexões e estratégias que vieram a conformar, não só a cultura jornalística, mas o entendimento da importância atribuída aos diferentes processos formativos voltados para o exercício desta profissão.

A existência de intensos e crescentes processos nos quais tecnologias são convertidas em meios de comunicação, geram transformações na própria ambiência social, especialmente em sua organização e formas de interação. Passam a permear por suas novas lógicas, a atividade das instituições e suas relações com os atores sociais, afetando suas práticas com novos processos tecnodiscursivos de construção de inteligibilidades. Tal fenômeno produz a transformação da "sociedade dos meios" na "sociedade da midiatização" na qual o modo de organização e de funcionamento de suas instituições e dos atores, leva em conta a existência dos meios, de suas lógicas e operações, em suma de uma nova cultura de produção de sentidos.

Esta nova realidade que resulta, particularmente do que se chama a "cultura da convergência" (JENKINS, 2009), repercute de modo complexo no âmbito da própria mídia jornalística. Particularmente, em suas rotinas, seus valores-notícias, no status dos seus atores, na incorporação dos leitores como novos agentes junto aos processos de produção da noticiabilidade, na relação com as fontes as quais, por conta da emergência de tecnologias, passam a usufruir de condições tecnológicas para "fiscalizar" o trabalho produtivo do jornalista. De modo específico, o lugar autoral do jornalista parece esmaecer diante da emergência da figura do amador (Keen, 2009), o que repercute também sobre a própria noção de acontecimento uma vez que, para elaboração da notícia, já não se exige o domínio de um sofisticado equipamento de codificação. Segundo determinada perspectiva, o processo de produção do acontecimento extrapolaria as fronteiras do dispositivo jornalístico, passando a depender de um conjunto
O lugar autoral do jornalista parece esmaecer diante da emergência da figura do amador (Keen, 2009) 
de transações e competências, e de novos contatos entre sujeitos (fontes, jornalistas, leitores, etc) reunidos em torno de novos mecanismos interacionais. Características do campo jornalístico sofrem profundas mudanças provocadas pela midiatização permeante à sociedade, de modo tal que a prática de "construção de acontecimento" não dependeria apenas das suas rotinas e dos fundamentos e de suas próprias fronteiras, mas também de complexas interfaces com outras práticas, em suma com o ambiente enquanto seu entorno, conforme lembra Luhmann:

A teoria dos sistemas recente (...) abandonou a sua perspectiva tradicional introduzindo uma referência explícita ao ambiente. A noção de ambiente não implica somente que algo mais existe fora do sistema em estudo. Não se trata de distinguir entre 'aqui' e em qualquer outro sítio. As estruturas e processos de um sistema só são possíveis em relação a um ambiente, e só podem ser entendidas se estudadas nesta relação. Assim é, pois só por referência a um ambiente é possível distinguir (num sistema dado) algumas funções como um elemento e outras funções como uma relação entre elementos. (Luhmann 2001:99).

Estamos diante de uma nova complexidade que afeta, particularmente, noções mais clássicas sobre a tarefa do jornalismo e o lugar do jornalista como selecionador de fato e mediador de contatos, assim como os fundamentos do trabalho metodológico de apuração e construção da notícia. Na medida em que o processo de produção do acontecimento, sendo atravessado por referências desta nova complexidade, se tornaria menos um trabalho isolado - autodependente do sistema jornalístico - e mais associado à dinâmica de relações ambiente-sistema.

Esta relação entre ambiente-sistema, acima descrita por Luhmann, que se destaca em novas práticas jornalísticas, como novas modalidades de interface entre o "fora e dentro", é comentada pelo jornalista Ricardo Noblat ao se reportar aos aspectos que envolvem a noticiabilidade no contexto da internet. Enfatiza os ângulos autorais, mas também as dinâmicas relacionais que balizam o funcionamento do trabalho jornalístico no âmbito, desta nova topografia. Diz:

Neste espaço sem regras, onde podemos utilizar os recursos da TV, do rádio e do jornal impresso, tudo pode - menos a lerdeza. Dou a notícia, de preferência em primeira mão, explico e analiso abrindo espaço para outros comentários. No blog, a notícia é uma troca: você oferece a informação e recebe de imediato a contestação, análise ou crítica. Quantas vezes eu mudo de opinião em razão desses comentários que recebo (...). Sem nenhuma interferência do Estado, tenho total liber-
Características do campo jornalístico sofrem profundas mudanças provocadas pela midiatização permeante à sociedade 
dade e independência para divulgar o que quero juridicamente segundo contrato, sou responsável pelo que divulgo e pelos comentários dos internautas. Possuo três moderadores com a função de evitar que esses comentários configurem crimes e com a missão de eliminar a baixaria. Os comentaristas brigam demais entre $\mathrm{si}^{1}$.

Diferentemente, porém do que afirma Noblat sobre a autoralidade, do trabalho jornalístico no blog, esta prática sofre outros constrangimentos, ainda que não destacados, são por ele lembrados, quando chama atenção para a existência de forças e de estratégias de regulação instituídas no ambiente (referências normativas e jurídicas), ale de outras que resultam do próprio sistema jornalístico, por exemplo os moderadores por eles apontados, enquanto novas formas de gate keepers. Temos assim, de modo didático, referências interessantes sobre as injunções destas complexidades que afetam o trabalho da noticiabilidade.

Certamente que o condicionamento do trabalho jornalístico à tais novas condições de produção, representadas por esta lógica de interfaces, não parece fácil para uma prática que quer continuar fazendo de sua autonomia um traço fundamental da sua identidade. O "escancaramento" de suas fronteiras para o ingresso nelas de novos atores, como fontes e leitores, enquanto novos cogestores no processo de produção da noticiabilidade, provoca repercussões sobre o sistema jornalístico. Este, num "instinto de sobrevivência" da sua instância mediadora, vai desenvolvendo estratégias típicas de um sistema autodescritivo de suas operações, culminando em práticas autorreferentes, ao chamar atenção para diferentes marcas da própria "realidade de construção". Ou seja, os processos de tecnointeração ensejados pela midiatização, favorecem novas formas de vínculos entre mídias e leitores, segundo desenhos de "contratos de leituras "que redesenham novos processos de noticiabilidade. Ao mesmo tempo enseja a emergência de protocolos pelos quais o jornalismo, chama atenção para sua existência, seu modo de funcionamento, e de modo especial, para a permanência da sua tarefa discursiva de produção da atualidade.

Tais práticas de manifestações de autorreferências ocorrem em diferentes temporalidades: naquelas intrínsecas ao processo de produção da noticiabilidade e, noutras decorrentes da primeira, que chamam atenção para virtudes, especialmente, aquelas dos seus produtos. Mui recentemente, o "Jornal Nacional" da Rede Globo de Televisão, na esteira das comemorações dos seus 40 anos, é convertido num noutro tipo de produto. Torna-se objeto de um livro publicado por editora do mesmo grupo de comunicação, tendo como autor o principal ancora daquele telejornal, Willliam Bonner. A autorreferencialidade ali se desdobra, pois a equipe

1 "No Blog Tudo pode", Jornal Pauta, n.156, p.9, Sindicato dos Jornalistas Profissionais de Minas Gerais, Belo Horizonte, maio de 2006. 
de produção do Jornal Nacional é metaforizada na capa do livro através de uma foto do casal-apresentador. Nela observa-se que a imagem da redação, enquanto referência ao processo produtivo da informação, aparece em segundo plano. Além destas marcas, a proposta editorial da publicação tem também um cunho autorreferente: ensinar as pessoas como é feito o Jornal Nacional².

\section{A formação do jornalista diante da midiatização}

Convém fazer uma certa associação entre a decisão do STF sobre a desobrigação do diploma e os contextos nos quais ela se procedeu, contextos estes que transcendem à racionalidade dos argumentos jurídicos.

Conforme pudemos ler no voto favorável a extinção da obrigatoriedade do diploma, pelo menos dois argumentos se destacam: em primeiro lugar, os pré-requisitos para o exercício da profissão por ele lembrados (sensibilidade e expressão). Tal escolha relega, por exemplo, a importância de mecanismos de outra ordem, como o trabalho universitário. Em segundo lugar, o argumento do STF ao desconhecer a importância da universidade como espaço de formação de jornalistas recomenda como alternativa, que a tarefa de treinamento e preparação destes seria uma atividade confiada a esfera das próprias empresas. O ato do STF deixou à margem da sua decisão sérias questões epistemológicas suscitadas pelas transformações porque passam o exercício do processo de noticiabilidade.

$\mathrm{Na}$ ótica de experientes jornalistas, como a de Jean Daniel, editor principal da revista francesa Le Nouvel Observateur, os processos de capacitação e o reconhecimento da profissão de jornalistas estão em crise e ameaçados. E explica: "a possibilidade de qualquer pessoa responder a qualquer pessoa. Ou o fato de que todo mundo possa ser jornalista, e neste caso que os próprios jornalistas deixam de acreditar neles mesmo, porque são questionados a todo momento (...) todo itinerário de preparação, que terminava num estatuto de prestígio e autoridade do jornalista, está sendo destruído pela aparição repentina de alguém que encontra uma foto e a coloca na internet. E esta foto pode destruir alguém" ${ }^{3}$.

A decisão do STF maximiza as possibilidades dos ideais formativos das empresas, ao recomendar que o atual treinamento feito pelas universidades venha a ser realizado por iniciativas da própria organização midiático-empresarial. Relevou tal decisão experiências de muitas décadas nas quais a universidade brasileira experimenta processos formativos - com erros e acertos - e que lhes credenciam como uma das mais importantes agencias dedicada ao ensino do jornalismo. Não fora esta referência suficiente, convém agregar a existência dos programas de pós-

${ }^{2}$ BONNER, Willian. Jornal Nacional: Modo de fazer. Rio de Janeiro: Editora Globo, 2009.

${ }^{3}$ Notícia urgente, Caderno Mais, Jornal Folha de São Paulo, 01.03.2005. 
graduação, como centros de pesquisa voltados para realização de altos estudos, para o ensino e a pesquisa; as várias entidades científicas onde se reflete sobre a pesquisa acerca do campo jornalístico, formando um dos mais apreciáveis nichos de estudos sobre o jornalismo, no âmbito internacional. No lugar delas, duas ou três referências sobre o ensino universitário de outros países, e que serviram possivelmente como argumento para alimentar o voto do STF.

A complexidade imposta pela midiatização ao sistema jornalístico - à sua cultura e rotinas; seus atores; as relações com fontes e leitores; em suma, os seus vínculos com a ambiência - precisa ser refletida com rigor, uma vez que, estando ambiente e sistema em relação, e vivendo processos de interações, significa que tal problemática ultrapassa a esfera de soluções puramente instrumentais. Particularmente, a questão relacionada com a formação dos jornalistas, tendo como cenário o ambiente da midiatização, não pode ser reduzida a uma estreita dimensão regulatória, na medida em que tal desafio fique restrito ao domínio das empresas de comunicação, retirando-se da universidade a competência (treinamento, pesquisa e o estudo teórico) para exercer o poder formativo que lhe é inerente. Se a profissão de cozinheiro não precisa de diploma para o seu exercício, conforme o STF, a de treinador de futebol requer certificações, pelo menos em alguns países europeus, e parece ser uma tendência a ser exigida no Brasil, nos próximos tempos ${ }^{4}$. Parece-nos que a profissão de jornalista enfrenta no mundo atual muitas complexidades. Isto requer cuidados sistemáticos nos processos que envolvem a formação dos seus quadros, requisitos aos quais se agregariam a capacidade de expressão redacional e a sensibilidade como recursos. O exercício da autonomia, como um dos requisitos que o campo jornalístico lida como um fundamento de sua profissão, não se trata de um problema apenas jurídico, mas também epistemológico. $\mathrm{O}$ jornalista e seu campo gozarão deste fundamento na medida em que sejam providos de equipamentos técnico-ético-estéticos que garantam outros tipos de relações com fontes e leitores, além da importância dos protocolos técnicos. Neste sentido, não temos certezas se as preocupações formativas das empresas venham a ser mais competentes e sólidas do que as que propõem o ensino universitário.

\section{Universidade e complexidade curricular}

Enquanto do lado de cá do Atlântico novas regulações são estabelecidas para submeter a atividade pública do jornalismo às lógicas e motivações das regras privadas das empresas de comunicação - no Atlântico, do lado de lá, e no Pacífico - também um outro debate se desenvolve. Não fica restrito à setores cor-

${ }_{4}$ "CBF criará licença para técnicos", jornal Folha de São Paulo, Esporte, p.D1, $11 / 08 / 2009$. 
porativos e vozes isoladas da academia, mas são empunhados por reflexões preocupadas com o funcionamento e o destino do espaço público, a partir das injunções da midiatização sobre diferentes práticas sociais. Habermas, na Alemanha preocupa-se com a horizontalização dos processos de interação da internet ao fazer desaparecer a singularidade do ponto de vista do intelectual (HABERMAS, 2006). Nos Estados Unidos, o futuro do jornalismo ocupa as reflexões das grandes catedrais universitárias, como a Universidade de Columbia, onde seus schollars em jornalismo reconhecem a importância da internet como suporte de dinamização do jornalismo, mas a partir do papel intransferível deste ator de organização de conteúdos, que é o jornalista (Pavelik, 2004). Num recente debate via mídia, envolvendo um dos experts da comunicação digital Steven Johnson e o Prêmio Pulitzer e professor de Princenton Paul Starr, a questão desta nova ecologia comunicacional e discursiva, esteve em pauta. E uma das temeridades sustentadas por Starr, é a emergência do amador, e dos seus efeitos para pauperização do processo formativo do jornalista, em suma suas repercussões sobre o espaço público. Diz ele: "o novo ambiente da mídia provavelmente levará a um abismo maior entre a minoria que se interessa intensamente pela vida pública e o número consideravelmente maior de pessoas que se afasta por completo da esfera pública, informando-se pouco sobre política e importando-se menos ainda com ela"5. Faz uma certa relação entre o enfraquecimento da profissão de jornalista e a emergência de uma "sociedade de informação estratificada", e a ascensão do "eu diário".

$\mathrm{O}$ ato do Supremo Tribunal Federal (STF) ao desqualificar a natureza simbólica do diploma universitário não deve produzir naqueles que se preocupam com tal questão apenas uma atitude reativa. Pelo contrário, deve nos estimular a construir argumentos que possam se contrapor a concepção sobre requisitos que normatizariam o ato jornalístico, conforme recomendou o Tribunal. Formular de modo mais complexo a importância da formação jornalística subordinada à tradição universitária, do que apenas às lógicas das empresas. Pensar a formação como um processo que entende o jornalismo como uma atividade pública, e cuja labuta dos seus atores esteja referida pelas lógicas e as epistemologias do conhecimento, do que, necessariamente, pelas regras regulatórias de empresas jornalísticas. A autopoiésis engendrada no ambiente restrito de uma empresa é importante para sua experiência tecno-estética e ética, mas não substitui padrões incomparavelmente, mais abrangentes, como àqueles que orientam o ensino do jornalismo, da perspectiva universitária. A noção de acontecimento, categoria central do processo de noticiabilidade, requer um treinamento mais complexo da parte dos

5 "Mídias em guerra", de Steven Johnson, um dos pioneiros da internet; e Paul Starr, Prêmio Pulitzer e professor de Sociologia em Princenton, travam um debate acirrado sobre o futuro do jornalismo e o acesso à informação". Jornal Folha de São Paulo, Caderno Mais, 10/05/2009).

\footnotetext{
Estudos em Jornalismo e Mídia - Ano VI - n. 2 pp. 149 - 159 jul./dez. 2009
} 
candidatos ao jornalismo, do que os estágios empresariais nos quais se modelizam os parâmetros sobre a noção de acontecimento, e que são definidos apenas pela economia discursiva e enunciativa do processo produtivo de cada grupo editorial. Os marcos gerais que orientam a formação jornalística não podem dar lugar ao adestramento pretendido no âmbito das empresas e que visa transformar o jornalista em executor de "contratos de leituras"; ou seja, processos que vão vincular mídia e leitores a uma certa noção de noticia, inibida ao marco de cada corporação jornalística-empresarial. Sem deixar de reconhecer que cada instituição jornalística pode e deve desenvolver procedimentos que experimentem o seu modelo de enunciação da realidade, devemos, contudo, admitir também que os "processos litúrgicos" que orientam a formação de jornalistas transcendem os treinamentos privados que visam possibilitar a educação de jornalistas, e também dos leitores, voltada para a lógica de um meio específico. Os cuidados pedagógicos mais amplos que envolvem o treinamento do jornalista, visando capacitá-lo para o percurso de sua "aventura interpretativa", não podem ser reduzidos às "liturgias privadas". Tais treinamentos são importantes - e devem ser estimulados - como atividade complementar. Poder-se-ia objetar alegando que a ascensão das narrativas dos leitores no espaço dos jornais torna o trabalho de produção da realidade mais plural (dialógico) com manifestações de outras vozes que não estão necessariamente, sob o controle do dispositivo produtivo. Mas esta é uma problemática que tem que ser estudada com mais cuidado, pois o avanço do "jornalismo colaborativo" ou do "jornalismo cidadão", não ultrapassa as fronteiras dos mecanismos regulatórios que definem até onde podem avançar os atores-leitores na tarefa de co-produção da notícia. Esta é apenas uma dentre outras questões geradoras de novas matérias e de conteúdo de estudos que deveriam alimentar os novos currículos de formação.

A defesa do diploma universitário, enquanto um certificado de reconhecimento, não se trata da valorização de um dispositivo cartorial. Pelo contrário, trata-se do reconhecimento de que a universidade é um espaço de treinamento teórico-metodológicotécnico-ético, etc. Reúne credenciais mais abrangentes do que os cursos de atualização com que as empresas pretendem resgatar jovens jornalistas do "tempo perdido", quando estes frequentaram os bancos universitários, adestrando-os aos seus modelos tecno-discursivos, em termos editoriais. Há um contraponto também perigoso e que consiste na eleição de desenhos curriculares endógenos ao universo jornalístico, sob alegativa de que é possível formar jornalistas apenas com os recursos existentes no âmbito das fronteiras das teorias e metodologias jornalísticas. Esta parece não ser a tradição de algumas experiências, onde
A defesa do diploma universitário, enquanto um certificado de reconhecimento, não se trata da valorização de um dispositivo cartorial. 
a problemática do diploma não se coloca como exigência. Seus fundamentos sustentam a tese segundo a qual os "requisitos fundamentais da formação jornalística são culturais, humanísticos \{envolvendo\}competências cultural, comunicacional, profissional e tecnológica" (Mesquita, 2004: 191). A questão da qualificação do jornalista requer, sem dúvida, sensibilidade e domínio da expressão redacional, mas não como as únicas pré-condições. Subsistem desafios e que chamam atenção para existência de outros âmbitos que podem fornecer outros instrumentos de boa formação. Ao invés de respostas prontas, pergunta-se: "quem deve desenvolver os planos de estudos (...) e qual seria a educação de excelência para que o profissional se forme num critério próprio em beneficio da qualificação da noticia" (Martini, 2004: 35).

Os tempos e as dinâmicas da midiatização suscitam admitir que o jornalismo não pode ser pensado apenas como prática profissional, mas "de modo integral, em sua configuração social, política, econômica, tecnológica, como discurso, narração, imaginário, técnica e manifestação cultural" (Silva, 10: 2009).

As condições sobre as quais se tece o ato de noticiabilidade se complexificam, por força das incidências dos processos crescentes de midiatização, transformando o próprio status da notícia, enquanto principal objeto do jornalismo. O trabalho de tessitura do acontecimento, ainda que se modelize segundo as referências das rotinas produtivas, é cada vez mais "insuflado" e permeado pelos postulados e lógicas da midiatização, e cujas operações não se encontram, apenas ali, acantonadas no sistema jornalístico, já que permeiam o ambiente como um todo. Nestas condições, se o objeto do jornalismo se complexifica diante de tais mutações, o mesmo ocorre com o corpo teórico e as proposições metodológicas que sustentam o seu edifício formativo, bem como as novas exigências que se impõem ao exercício desta modalidade de trabalho tecno-simbólico.

Nas observações acima, que procedem de reflexões acadêmicas e com apreciável conhecimento do labor do jornalismo, repousam indagações e sugestões que podem se constituir em insumos para um debate e estudo, enquanto sugestões valiosas com vistas às ações que possam orientar novas formulações de desenhos curriculares.

\section{Referências}

ALSINA, Miguel. A construção da notícia. Petrópolis:Vozes, 2009.

BERGER, Christa; MAROCCO, Beatriz (Orgs.). A era glacial do jornalismo: teorias sociais da imprensa. Porto Alegre: Sulina, 2008.

DANIEL, Jean. Notícia urgente. In: Caderno Mais! Jornal Folha de SP, 01/03/2005. 
HABERMAS, Jürgen. O caos da esfera pública. In: Caderno Mais! Folha de São Paulo, 18/08/2006.

JENKINS, Henry. A cultura da convergência. São Paulo: Aleph, 2009.

KEEN, Andrew. O culto do amador. Rio de Janeiro: Jorge Zahar, 2009.

MORIN, Edgar (Org.) L`Évènement. Comunications. Paris: Seuil, n.10, 1972.

LUHMANN, Niklas. A improbabilidade da comunicação. Lisboa: Paisagens, 2001.

LUHManN, Niklas. A realidade da comunicação. Petrópolis: Vozes, 2005.

LUHMANN, Niklas. Introdução à teoria dos sistemas. Petrópolis: Vozes, 2009.

MAROCCO, Beatriz; BERGER, Christa. A era glacial do jornalismo. Teorias Sociais da Imprensa. Porto Alegre: Sulina, 2008.

MARTINI, Stella; LUCHESSI, Lila.(Orgs.). Los que hacen la noticia. Buenos Aires: Biblos, 2004.

MARTINI, Stella. Periodimos, noticia e noticiabilidad. Buenos Aires: Norma, 2000.

MESQUITA, Mário. O quarto equívoco. O poder dos medias na sociedade contemporânea. Coimbra: Minerva, 2004.

PAVLIK, John V. El periodismo y los nuevos medios de comunicaciòn. Barcelona: Paidòs, 2005.

"No blog tudo pode". In: Pauta, Jornal do Sindicato dos Jornalistas Profissionais de MG, ano XXII, n.156, maio de 2006, p.9.

SANTIAGO, Emiliano. Imprensa e Poder. São Paulo: HUCITC-UFBA, 1996.

SILVA, Gislene. De que campo do jornalismo estamos falando? Anais do XVIII Encontro Anual da Compós (Associação dos Programas de Pós-Graduação em Comunicação). Belo Horizonte, MG: PUC Minas, de 2 a 5 de junho de 2009.

SODRE, Muniz. A narração do fato. Notas para uma teoria da ação. Petrópolis: Vozes, 2009.

SOSTER, Demétrio; PICCININ, Fabiana e FELIPPI, Ângela. (Orgs.). Metamorfoses Jornalísticas. Santa Cruz do Sul: EDUNISC, 2007.

SUAREZ, Adriana. Informacion: Se puede saber lo que pasa? Buenos Aires: Normas, 2005.

VERÓN, Eliseo. La Mediatizacion. Buenos Aires: UBA, Oficina de Publicacion, n.4, 1997.

Recebido em 2 de setembro de 2009

Aprovado em $1^{\circ}$ de outubro de 2009 